\title{
自然科学基金项目进展专栏
}

论 文

\section{瓦里关大气 $\mathbf{C H}_{4}$ 浓度变化及其潜在源区分析}

张芳 $^{(1)}$, 周凌晞 ${ }^{(2)}$, 许林 $^{(2)}$

(1) 北京师范大学全球变化与地球系统科学研究院, 北京 100875 ;

(2) 中国气象科学研究院大气成分研究所, 中国气象局大气化学重点开放实验室, 北京 100081

* 联系人, E-mail: zhoulx@cams.cma.gov.cn

收稿日期: 2012-08-28; 接受日期: 2012-11-17

国家自然科学基金(批准号: 41175116)、国家重点基础研究发展计划(编号: 2010CB950601, 2013CB955801)和科技部国际科技合作项目(编 号: 2011DFA21090)资助

摘要利用尺度校正和更新的 2002 2006 年瓦里关多年大气 $\mathrm{CH}_{4}$ 浓度资料, 进行了其浓度 时空变化及其潜在源区分析研究. 局部近似回归法䇻分的大气 $\mathrm{CH}_{4}$ 浓度本底数据百分比为 $\sim 58 \%$, 表明其受到较强的区域源和汇的影响. $\mathrm{CH}_{4}$ 本底浓度中值为 $1831.8 \mathrm{ppb}, 10 \%$ 和 $90 \%$ 的 $\mathrm{CH}_{4}$ 浓度数据百分位值分别为 1820.7 和 $1843.5 \mathrm{ppb}$. 未经篮分的大气 $\mathrm{CH}_{4}$ 浓度波动大, 达到了 $200 \mathrm{ppb}$; 本底浓度波动小 (约 $38 \mathrm{ppb}$ ), 反映了瓦里关大气 $\mathrm{CH}_{4}$ 浓度受到较强的区域源汇影响. 2002 2006 年期间不同季节大气 $\mathrm{CH}_{4}$ 浓度日变化规律明显, 其变化特征是源汇强度变化和对 流层大气扩散输送条件相互作用的结果. 大气 $\mathrm{CH}_{4}$ 多年平均季节变化呈夏季高(6 8月达到最 大值), 冬春低的特征, 与美国莫纳罗亚山和 Niwot 岭呈反相位, 一方面可能是夏季瓦里关地 区排放源增强(居民放牧增多)和以来自西宁和兰州地区的气流为主导的污染物输送而导致其 浓度抬升, 另一方面瓦里关光化学作用较弱, 与美国莫纳罗亚山和 Niwot 岭相比, $\mathrm{CH}_{4}$ 的汇较 弱. 轨迹聚类和潜在源区分析表明, 大气 $\mathrm{CH}_{4}$ 浓度高值与来自青海西北部(尤其是格尔木地区) 和瓦里关东南或东部(西宁和兰州一带) 的空气团轨迹关系密切, 是 $\mathrm{CH}_{4}$ 潜在的源区; 其浓度低 值则对应于来自西藏西北部、青海和新疆南部地区的空气团, 反映了该方向的气流相对清洁. 注意到夏季来自甘肃或宁夏黄河沿岸的农业区(如水稻种植区)空气团使 $\mathrm{CH}_{4}$ 浓度抬升明显, 显示了其农业排放源. 本文的研究将对准确估算 $\mathrm{CH}_{4}$ 区域源汇强度、全面理解温室效应的尺 度及预测未来全球变化具有重要意义.

甲烷 $\left(\mathrm{CH}_{4}\right)$ 是大气含量仅次于 $\mathrm{CO}_{2}$ 的温室气体, 也是《京都议定书》规定的需要减排的温室气体之一. 在大气中的滞留时间约 12 年 ${ }^{[1,2]}$, 其红外吸收带处在 地球长波辐射的峰区范围内, 因此能够强烈地吸收 地球长波辐射而具温室效应. 以 100 年计, 其单个分
子对温室效应的贡献约为 $\mathrm{CO}_{2}$ 的 25 倍, 对全球总 辐射强迫的贡献为 $18.1 \%$ (http://www.wmo.int/pages/ prog/arep/gaw/ghg/GHGbulletin.html). 冰芯记录的过 去 160000 年 $\mathrm{CH}_{4}$ 浓度为 $300 \sim 700 \mathrm{ppb}\left(10^{-9} \mathrm{~mol} / \mathrm{mol}\right)^{[3]}$. 本底站点观测结果表明, 自工业革命开始以来, 对流

中文引用格式: 张芳, 周凌晞, 许林, 等. 瓦里关大气 $\mathrm{CH}_{4}$ 浓度变化及其潜在源区分析. 中国科学: 地球科学, 2013, 43: 536-546

英文引用格式: Zhang F, Zhou L X, Xu L. Temporal variation of atmospheric $\mathrm{CH}_{4}$ and the potential source regions at Waliguan, China. Science China: Earth Sciences, 2013, 56: 727-736, doi: 10.1007/s11430-012-4577-y 
层本底大气 $\mathrm{CH}_{4}$ 浓度从 $700 \mathrm{ppb}$ 增加到约 $1800 \mathrm{ppb}$; 而 WMO/GAW 长期观测资料显示, 2009 年全球本底 大气 $\mathrm{CH}_{4}$ 平均浓度达到了 $1803 \mathrm{ppb} . \mathrm{CH}_{4}$ 通过自然 ( 40\%, 如湿地和白蚁)和人类活动( $60 \%$, 如水稻种 植、反刍动物呼吸、化石燃开发、垃圾填埋和生物质 燃烧等)排入大气. 与羟基 $(\mathrm{OH})$ 反应是其主要的汇. 开展 $\mathrm{CH}_{4}$ 浓度观测及源汇的研究, 对准确估算、预测 大气 $\mathrm{CH}_{4}$ 浓度及其变化趋势, 全面理解与预测未来 全球变化及温室效应的尺度与规模具有重要意义, 估算和预测当前和未来大气 $\mathrm{CH}_{4}$ 的源与汇及其变化 趋势已成为国内外研究的一个热点.

大气 $\mathrm{CH}_{4}$ 浓度的长期观测始于 1978 年 ${ }^{[4 \sim 6]}$. 国际 固定站点观测网络对于大气 $\mathrm{CH}_{4}$ 在线连续观测最早 多采用气相色谱法(GC-FID). 我国青海瓦里关自 1994 年开始大气 $\mathrm{CH}_{4}$ 浓度在线观测, 采用了 WMO 推荐的 GC-FID 法. 随着对本底大气温室气体观测研 究工作的持续和深入, 观测方法和技术也在不断发 展. 如国际上最新研发的光腔衰荡技术(CRDS)用于 快速高分辨率测量 $\mathrm{CO}_{2}$ 和 $\mathrm{CH}_{4}{ }^{[7]}$, 已首次应用于在我 国 4 个 GAW 本底站在线观测大气 $\mathrm{CO}_{2}$ 和 $\mathrm{CH}_{4}$ 浓度 ${ }^{[8]}$. 各国有关机构已相继在全球不同经纬度地区开展温 室气体观测并积累了长期时间序列资料. $\mathrm{WMO} / \mathrm{GAW}$ 的建立旨在更系统地开展温室气体等大 气成分的长期观测, 逐步形成覆盖全球各纬度带的 观测网, 为相关研究提供可靠的观测资料.

大气 $\mathrm{CH}_{4}$ 主要有采样和在线两种观测方式. 国 际观测网络的实际经验表明, 在线观测频率高, 可实 时反映其浓度的动态变化, 捕捉在一定时期内的污 染气团事件及短时期内 (如 1 3 天)其输送路径. 利用 高分辨率的在线观测资料, 结合同化气象资料, 应用 后向轨迹模式获得污染物的长距离输送特征, 可得 到区域尺度上的源汇特征; 还可利用数值模式计算 更小区域尺度上的源汇通量. 而采样观测方式则可 通过选择在对流层大气混合层高度最高时采样, 为 确定温室气体的全球本底浓度值提供参考 ${ }^{[9]}$. 本文拟 利用瓦里关站 2002 2006 年大气 $\mathrm{CH}_{4}$ 在线观测资料 研究其时空变化, 并与国际同类站点资料互比, 揭示 其区域和全球特征; 并通过不同输送过程对大气 $\mathrm{CH}_{4}$ 浓度的影响及长距离输送特征, 为温室气体源汇的 模式估算及全球气候变化相关领域的深入研究奠定 基础.

\section{1 站点介绍}

瓦里关全球本底站 $\left(36^{\circ} 17^{\prime} \mathrm{N}, 100^{\circ} 55^{\prime} \mathrm{E}\right.$, 海拔高 度 $3816 \mathrm{~m}$ ) 是全球大气观测站网 27 个全球本底站之 - ${ }^{[10]}$, 也是目前欧亚大陆腹地唯一的大陆型全球本 底站. 瓦里关全球本底站地处青海省海南藏族自治 州共和县境内瓦里关山顶, 瓦里关山呈西北-东南走 向, 与山底的相对高差约 $600 \mathrm{~m}$. 瓦里关偏东方向约 $90 \mathrm{~km}$ 的湟水河谷地带是青海省省会西宁市所在地 (人口约 220 万), 并有多座高于 $4000 \mathrm{~m}$ 的山峰横亘其 间; 西侧约 $30 \mathrm{~km}$ 处河谷盆地恰卜恰镇为海南自治州 政府所在地 (人口 3 万); 北侧是青海南山和青海湖; 南面 $8 \mathrm{~km}$ 为龙羊峡水库. 瓦里关山及周围地区自然 环境以高原草甸和沙洲居多, 全区以牧业为主. 瓦里 关本底站冬季主导风向为西南, 夏季为东北、东南 $风^{[11,12]}$. 瓦里关站位于亚洲大陆腹地, 具明显的高原 大陆性气候, 受高海拔条件制约, 气温较低, 观测资 料可反映出欧亚大陆重要的源汇信息 ${ }^{[13,14]}$.

\section{2 仪器和方法}

瓦里关气相色谱甲烷在线观测系统(GC-FID) 由 带有氢火焰离子化检测器和镍催化剂管的 HP5890气 相色谱仪、高压铝瓶和钢瓶 $\mathrm{CH}_{4}$ 工作标气、高纯氮气 (99.999\%)、高纯氢气( $99.999 \%)$ 及零气发生器等组成. 系统的采样口均设在瓦里关 $89 \mathrm{~m}$ 采样塔的 $80 \mathrm{~m}$ 高处, 其控制、测量、参比气、标气和数据采集等部分位于 瓦里关站实验室内. 有关该系统的测量原理、系统设 计和运行、标定等可参见有关文献 ${ }^{[15]}$. 系统 2001 年 之前采用样品/外部事件控制器和积分仪进行自动控 制和数据采集. 2001 年 9 月对系统升级改造, 由色谱 工作站自动控制和采集数据. 空气样品分析频率为 每天 168 次; 通过多口选择阀控制, 每分析 3 次空气 样品, 穿插分析 1 次工作标气. 为避免 GC-FID 系统 的标气中 $\mathrm{CH}_{4}$ 浓度漂移对观测值的影响, 采用站标 (CA01082，CA01465 和 CA01462)每 3 4 月左右对工 作标气进行标定, 获得校正的标称浓度值. 实际空气 样品采用工作标气校正. 因采用峰高计算 $\mathrm{CH}_{4}$ 浓度 的精度和准确度略好于用峰面积计算, 因此采用峰 高进行定量. 系统对 $\mathrm{CH}_{4}$ 的检测精度优于 $\pm 5 \mathrm{ppb}$, 准 确度在 $\pm 10 \mathrm{ppb}$ 内. 本文只对升级为色谱工作站的 $\mathrm{CH}_{4}$ 观测数据进行讨论. 
将已知标称浓度的标气(即目标气) 作为空气定 期测量分析, 可监视和诊断系统运行状况. 图 1 为对 1 瓶 $\mathrm{CH}_{4}$ 浓度接近实际空气浓度的目标气测量的长期 波动和变化, 可见大于 $90 \%$ 的偏差值均落在 $\pm 10 \mathrm{ppb}$, 说明该系统测量大气中的 $\mathrm{CH}_{4}$ 具有较好的稳定性. 因仪器故障, 房屋修缮停机以及标定等, 该系统在 4 年的观测期间(2003 2006 年)约有 20\%缺测率.

\section{3 讨论与结果}

\section{1 大气 $\mathrm{CH}_{4}$ 时间序列及本底值篮分}

因不同站点的地理位置、地形地貌和环境状况等 有很大差别, 应确定观测资料的时空代表性, 区分不 受局地或区域源汇影响的本底值, 方可进一步结合 数值模式研究其源汇. 这里所涉及的本底浓度是指 大气混合均匀, 且不受区域或局地污染源影响时所 观测的 $\mathrm{CH}_{4}$ 的浓度值, 可反映其长期变化趋势和季 节变化特征. 非本底浓度是指受到近地层大气区域 或局地污染源或消解汇的影响的浓度值, 通常会在 短时期内引起浓度的显著变化, 如因人为活动排放 引起 $\mathrm{CH}_{4}$ 浓度的迅速抬升. 一些研究采用统计学方 法对长时间序列的资料进行本底值的笁分, 如采用 非线性二次叠加谐波变换拟合, 将远离拟合曲线(残 差较大值)的观测值过滤掉, 反复逼近回归, 保留的 值即区分为具本底特征的值, 而过滤掉的值为非本 底值. 本研究将局部近似回归法(Robust Estimation of Background Signal, REBS)应用到瓦里关大气 $\mathrm{CH}_{4}$ 时 间序列的本底值篮分研究中, 该方法已与国际观测 网络 AGAGE 和美国 NOAA 所采用的方法进行了对
比 $^{[16]}$, 证实可用于长期观测数据的本底值篮分. 该方 法的主旨是对在一段较短时间内对观测值进行估计, 并且考虑 $\mathrm{CH}_{4}$ 浓度长期或短期的微小变化(日变化和 季节变化), 逐步逼近回归拟合, 因此长期趋势、季节 变动、循环变动等与时间序列关系密切的变量对时点 值不会产生影响 ${ }^{[17]}$. 本底值为假设大气均匀混合状 态的值, 因此任何源或汇的因素只会增大或降低本 底值.

图 2 是采用局部近似回归法 $\mathrm{CH}_{4}$ 的本底浓度值 篮分结果(2002 年 1 月 2006 年 12 月). 用这种方法篮 分的 $\mathrm{CH}_{4}$ 本底数据百分比约占原始有效数据的 $58 \%$, 与前期结合地面风进行本底数据篎分的研究结果相 似 ${ }^{[10]} ; 26 \%$ 的数据为源排放浓度值(受区域或局地排 放源的影响), 约 $16 \%$ 的资料代表了 $\mathrm{CH}_{4}$ 吸收浓度值 (主要受区域吸收汇的影响), 表明在观测期间瓦里关 地区大气受到较强的区域或局地排放源和吸收汇的 影响. $\mathrm{CH}_{4}$ 本底浓度中值为 $1831.8 \mathrm{ppb}, 10 \%$ 和 $90 \%$ 的 $\mathrm{CH}_{4}$ 浓度数据百分位值分别为 1820.7 和 $1843.5 \mathrm{ppb}$. 未经笛分的大气 $\mathrm{CH}_{4}$ 浓度波动大，达到了 $200 \mathrm{ppb}$; 大气 $\mathrm{CH}_{4}$ 本底浓度波动小 (约 $38 \mathrm{ppb}$ ), 反映了瓦里关 大气 $\mathrm{CH}_{4}$ 浓度受到区域源汇的较大影响.

\section{2 $\mathrm{CH}_{4}$ 日变化及其季节差异性}

图 3 是 2002 2006 年期间春、夏、秋和冬季瓦里 关大气 $\mathrm{CH}_{4}$ 日平均变化(0:00 23:00, 北京时). 不同 季节大气 $\mathrm{CH}_{4}$ 浓度均呈较明显的日变化, 日变化规 律和幅度且具有季节差异性. 春季, 夜间至清晨 (0:00 08:00)期间，大气 $\mathrm{CH}_{4}$ 浓度夜间(0:00 6:00)变

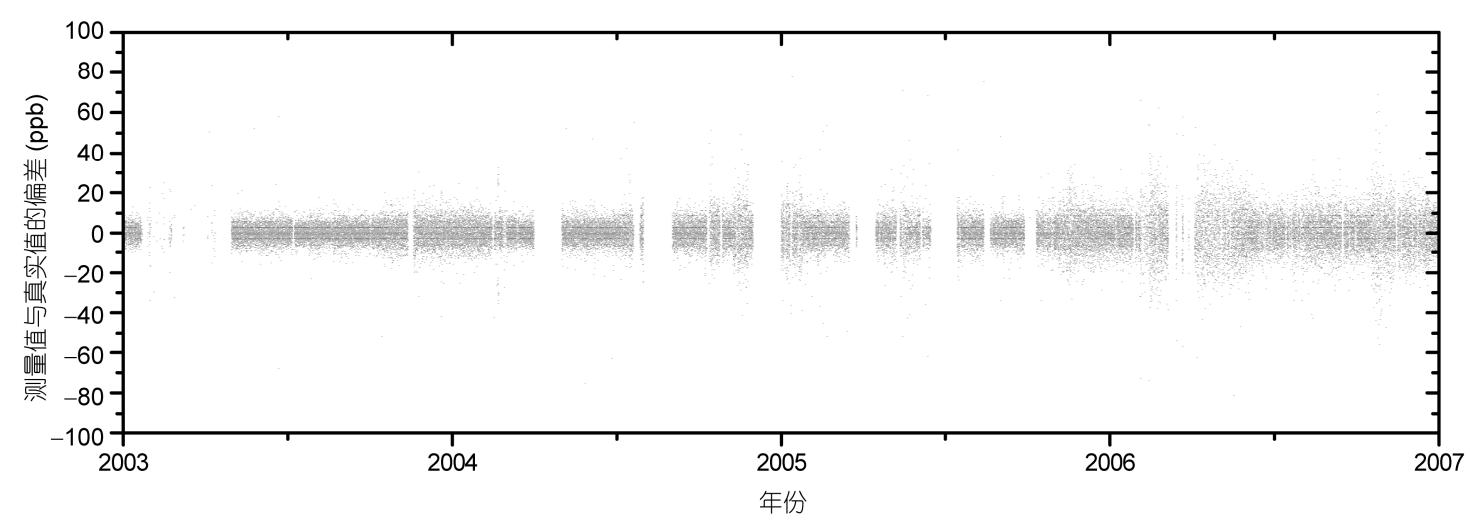

图 1 瓦里关 5890GC-FID 系统测量 $\mathrm{CH}_{4}$ 的目标气波动情况 


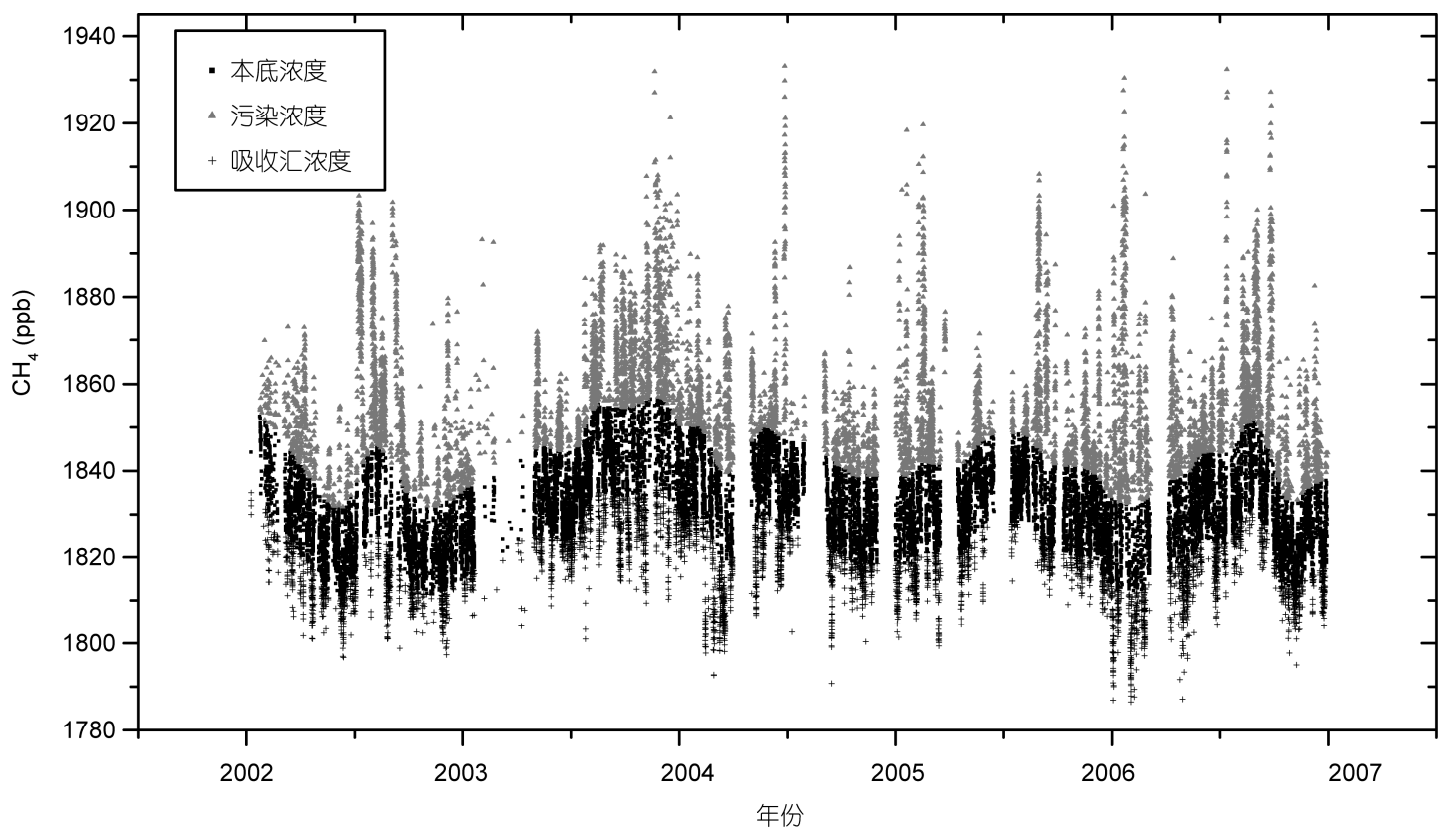

图 2 大气 $\mathrm{CH}_{4}$ 时间序列
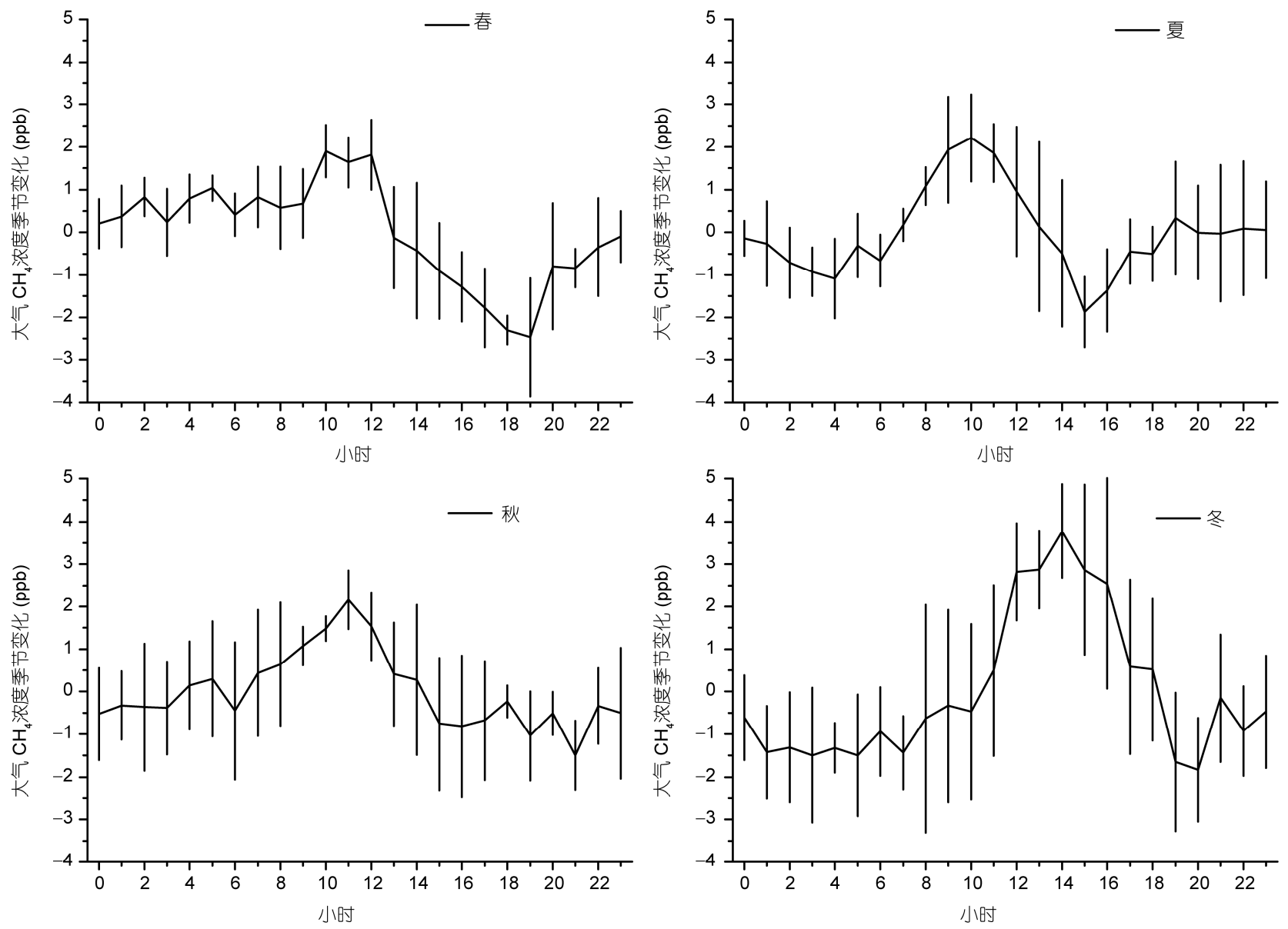

图 3 不同季节瓦里关大气 $\mathrm{CH}_{4}$ 浓度多年平均日变化 
化较为平稳, 08:00 之后略有抬升, 11:00 12:00 左右 出现下降趋势, 18:00 左右降至最小值, 之后又缓慢 上升. $\mathrm{CH}_{4}$ 呈这种变化的原因可能是午后太阳直射, 温度升高, 对流增强, $\mathrm{CH}_{4}$ 由地面向高空的扩散加快, 导致白天大气 $\mathrm{CH}_{4}$ 浓度有所降低, 并在傍晚出现最 低值; 夜间大气边界层比较稳定, 近地面温度比高空 低, 这种逆温效应使 $\mathrm{CH}_{4}$ 不易向高空扩散而累积, 因 此夜间浓度较高. 夏季, 夜间至清晨 (0:00 06:00)期 间, 大气 $\mathrm{CH}_{4}$ 浓度变化较为平稳, 06:00 之后有所抬升, 11:00 12:00 左右达到峰值, 之后出现下降趋势, 15:00 16:00 左右降至最小值, 之后又开始缓慢上升. 出现这种变化的原因是: 由于夏季牧民放牧及其他 活动比春季频繁, 导致在上午至午间出现较明显的 峰值. 此外, 夏季温度高, 白天对流较春季增强, 大 气中的 $\mathrm{CH}_{4}$ 更易扩散, 导致 $\mathrm{CH}_{4}$ 浓度随之快速下降. 夜间因逆温效应, 使 $\mathrm{CH}_{4}$ 浓度累积而略有抬升. 秋季, 大气 $\mathrm{CH}_{4}$ 浓度日变化总体呈白天高(10:00 12:00 达到 一天之中的最高值), 夜间及清晨略低的单峰特征, 总体上日振幅较小, 表明秋季 $\mathrm{CH}_{4}$ 浓度受局地源汇 及气象条件的影响较小. 冬季, 大气 $\mathrm{CH}_{4}$ 在夜间和清 晨呈平稳变化, 浓度较低, 14:00 15:00 左右出现峰值, 可能与冬季牧民外出放牧较晚导致峰值比其他季节 有所延迟. 总体上, 瓦里关大气 $\mathrm{CH}_{4}$ 浓度日变化受到 局地源汇变化以及大气动力、热力学等综合因素的影 响, 有关其排放规律将结合上述因素开展进一步的 研究.

\section{3 多年平均季节变化}

为了评估区域本底 $\mathrm{CH}_{4}$ 季节特征及其本底状况 的全球代表性, 本文将经 $\mathrm{R}$ 篮分后的大气 $\mathrm{CH}_{4}$ 数据求
算术平均, 获得逐年月平均值, 然后将月平均数据采 用最小二乘法线性拟合去趋势, 获得多年平均季节 变化(图 4). 可以看出, 瓦里关大气 $\mathrm{CH}_{4}$ 季节变化较 明显, 呈夏季高(6 8 月达到最大值), 冬春低的特征, 多年平均季振幅约 $11 \mathrm{ppb}$. 瓦里关大气 $\mathrm{CH}_{4}$ 夏季高的 原因推测可能有 3 方面: (1) 夏季瓦里关地区放牧活 动增多, $\mathrm{CH}_{4}$ 的排放源增多. 已有研究表明青藏高原 自然放牧状况下牦牛甲烷排放量在 $(25.9 \pm 1.61)$ $(30.4 \pm 1.05) \mathrm{L} / \mathrm{kg}$ 之间 ${ }^{[18]}$, 是大气 $\mathrm{CH}_{4}$ 的重要的源. 据 估计中国 $\mathrm{CH}_{4}$ 排放总量中反刍动物占了 $20 \%$ 以上 ${ }^{[19]}$, 仅次于水稻田排放, 可见其对大气 $\mathrm{CH}_{4}$ 浓度波动影 响较大. (2) 夏季瓦里关主导气流(来自西宁以及黄河 河谷工业地带)输送, 人为活动排放的 $\mathrm{CH}_{4}$ 通过长距 离输送也使夏季瓦里关大气 $\mathrm{CH}_{4}$ 浓度较高, 尤其 2000 年以来随着西部大开发, 位于瓦里关站东北和 北部的西宁和兰州地区工业发展迅速, 其 GDP 及人 口等都在迅速增加(例如, 2000 2006 年青海省 GDP 保持着 $10 \%$ 以上的快速增长), 这将导致 $\mathrm{CH}_{4}$ 的人为 排放源增强. (3) 夏季大气光化学作用虽然比冬季有 所增强, 但是瓦里关地区夏季光化学作用很弱, 与其 排放源相比对大气 $\mathrm{CH}_{4}$ 浓度的贡献可忽略不计. 冬 季 $\mathrm{CH}_{4}$ 浓度较低可能由于周边地区放牧活动的减少, 以及主导气流的转向(冬季气流由东南或东北转为西 南来向, 相对清洁), 因此冬春季 $\mathrm{CH}_{4}$ 浓度较低.

为了进一步探讨区域人类活动排放、陆地生物圈 源汇以及站点海拔高度等因素对大气 $\mathrm{CH}_{4}$ 浓度的影 响, 选择位于北半球的高海拔、中高纬度地区的 3 个 站点(美国莫纳罗亚山, 美国 Niwot 岭和德国楚格峰) 同期 $\mathrm{CH}_{4}$ 浓度资料的多年季节变化比较(图 5), 其中,

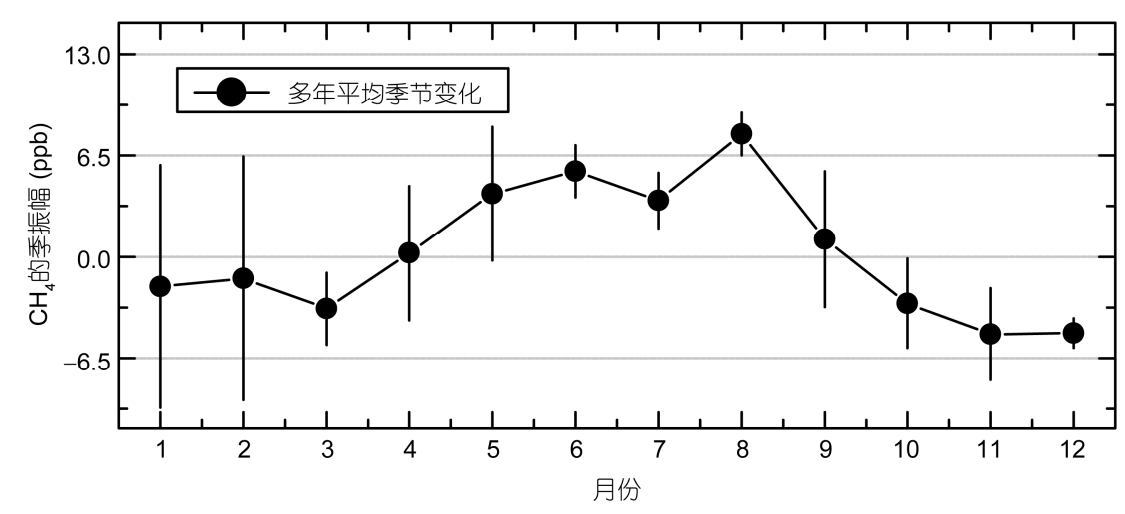

图 4 大气 $\mathrm{CH}_{4}$ 浓度月平均及多年平均季节变化 
美国莫纳罗亚山 $\left(19.52^{\circ} \mathrm{N}, 155.57^{\circ} \mathrm{W}, 3397 \mathrm{~m}\right.$ asl $)$ 地处 太平洋中部, 主要受海洋性气候控制, 受到人为活动 和植物生长的季节性变化的影响少. 美国 Niwot 岭 $\left(40.05^{\circ} \mathrm{N}, 105.59^{\circ} \mathrm{W}, 3523 \mathrm{~m}\right.$ asl, http://gaw.empa.ch/ gawsis/reports.asp)位于美国科罗拉多州 Boulder 西部 约 $35 \mathrm{~km}$ 处, 周边为高原冰川及冻土, 也为内陆高海 拔研究站点; 德国楚格峰站 $\left(47.25^{\circ} \mathrm{N}, 10.59^{\circ} \mathrm{E}, 2962\right.$ $\mathrm{m}$ asl, http://gaw.empa.ch/ gawsis/)位于德国南部最高 的楚格峰, 常年被积雪覆盖, 距离慕尼黑西南部 90 km. 3 个站点和瓦里关的大气 $\mathrm{CH}_{4}$ 浓度均由 GC-FID 法观测获得, 所采用的标准均为 NOAA04 标准尺 度 ${ }^{[20]}$. 由图可看到, 瓦里关大气 $\mathrm{CH}_{4}$ 月平均浓度的季 节变化与莫纳罗亚山和 Niwot 岭呈现完全不同的变 化趋势, 即瓦里关夏秋高、冬春低, 而莫纳罗亚山和 Niwot 岭则反之. 楚格峰站季节变化趋势不明显. 如 前所述, 瓦里关大气夏季 $\mathrm{CH}_{4}$ 浓度高主要是局地排 放源的增强(牧区居民放牧)和来自人口聚集和工业 发达区的远距离输送起所导致 ${ }^{[21]}$, 而美国莫纳罗亚 山和 Niwot 岭在夏季受到排放源的影响较小, 尤其是 莫纳罗亚山接近赤道地区, 夏季 $\mathrm{CH}_{4}$ 与 $\mathrm{OH}$ 自由基的 光化学反应较强, 且主要受海洋清洁气流来向的空 气团的影响, 因此其浓度较低. 瓦里关大气 $\mathrm{CH}_{4}$ 季振 幅约为 $11 \mathrm{ppb}$, 均远小于莫纳罗亚山 ( 30 ppb) 和 Niwot 岭( $\sim 30 \mathrm{ppb})$. 可能由于后两者夏季光化学作用
强, $\mathrm{CH}_{4}$ 浓度降低很明显, 季节振幅大. 由此可见, 不 同站点大气 $\mathrm{CH}_{4}$ 浓度季节变化的差异主要是不同下 垫面条件下其源汇相互作用的结果.

\section{4 聚类分析}

本论文采用由 NOAA(ARL)开发的 HYSPLIT4(Hybrid Single Particle Lagrangian Integrated Trajectory ${ }^{[22]}$, 即混合单粒子拉格朗日积分)传输、扩 散模式进行空气质点后向轨迹分析, 以通过输送路 径跟踪分析区域输送对瓦里关大气 $\mathrm{CH}_{4}$ 浓度的影响, 并推断其潜在源区. 轨迹模式所采用的气象资料是 NCEP(National Centers for Environmental Prediction) 的全球再分析资料. 本文计算后向轨迹的模式开始 时间为 00:00, 06:00, 12:00 和 18:00 UTC; 轨迹起始点 距地面 $500 \mathrm{~m}(\sim 600 \mathrm{mb})$, 因 $500 \mathrm{~m}$ 高度对应于该地区 的边界层中上部，风场能够反映边界层的平均流场 特征，进而可较准确地描述达到瓦里关地区的气团 移动路径; 相关研究也表明, 低层风场是决定周边地 区排放源贡献大小的主要因子. $600 \mathrm{~m}$ 以下风向随高 度变化较明显,一般在约 $300 \mathrm{~m}$ 以上为大尺度远距离 输送, 即受到周边源的影响显著区 ${ }^{[23]}$. 此外, 前期研 究表明 ${ }^{[13]}$, 根据瓦里关的地形特征, 选取 $500 \mathrm{~m}$ 作为 瓦里关及周边地区的主要输送层进行研究最为合适. 考虑到大气 $\mathrm{CH}_{4}$ 的大气寿命，由该点向后推 $5 \mathrm{~d}(120$

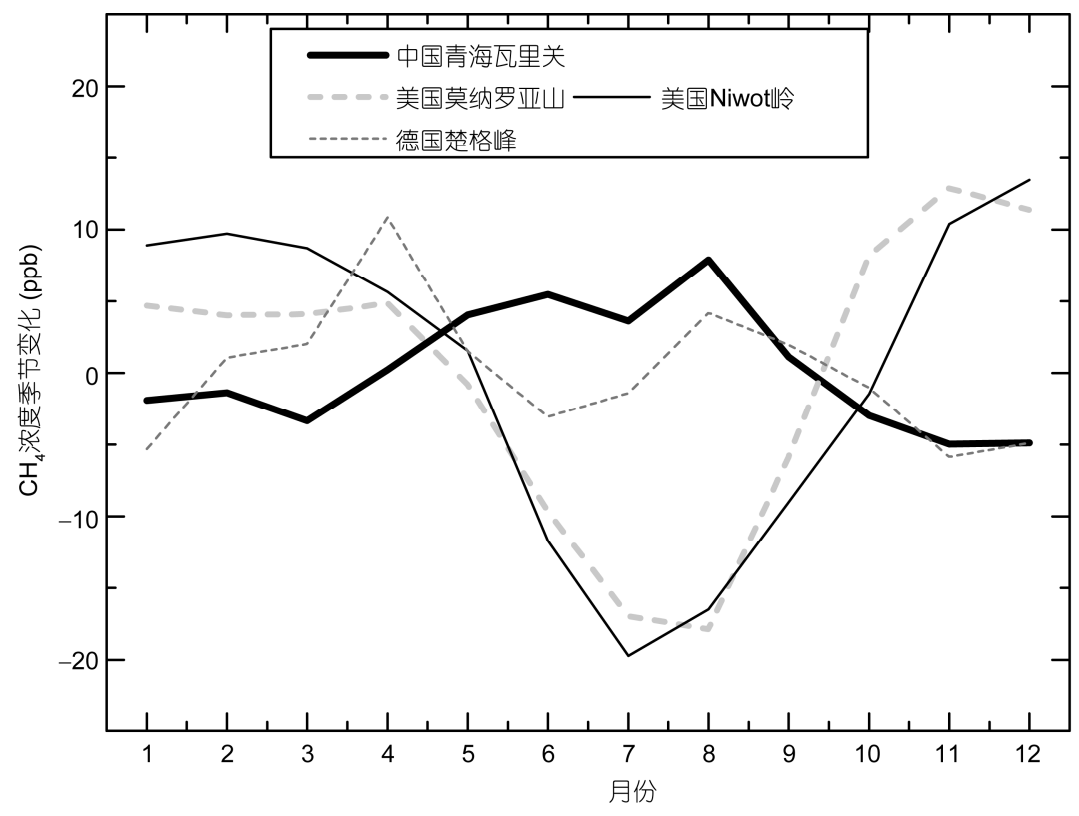

图 5 瓦里关与其他站点同期 $\mathrm{CH}_{4}$ 浓度资料的多年季节变化 
h) 计算其后向轨迹. 本文采用轨迹聚类分析的 Ward's 最小方差法 ${ }^{[24]}$, 将多条轨迹按照空间代表性 进行分类, 用于研究污染气团通过大气远距离输送 对瓦里关大气 $\mathrm{CH}_{4}$ 浓度的影响, 分析 2002 2006 年间 来自几类不同季节不同典型气团的大气 $\mathrm{CH}_{4}$ 小时平 均浓度的特征.

将 2002 2006 年春、夏、秋和冬的所有轨迹按照 季节进行聚类, 参与聚类分析的每个季节的轨迹数 均达到约 1800 多条, 根据每类轨迹所代表的典型空 间类型, 将其分为 4 类(图 6)到达瓦里关的典型输送 路径. 图中的百分比数字代表各类轨迹所占总轨迹 数的百分比, 数字表示轨迹聚类类型. 可见, 2002 2006 年期间, 春、秋和冬季来自新疆、青海、 新疆与西藏交界处和青海西北部的输送轨迹占总轨 迹数的百分比最大, 其中春季以第 2 类和第 3 类为主, 分别占 $55 \%$ 和 $26 \%$; 秋季主要以第 1 类和第 2 类为主, 占了总轨迹数的 $50 \%$ 和 $25 \%$; 冬季以 1 类和 3 类为主, 分别占总轨迹数的 $39 \%$ 和 $43 \%$, 这些轨迹较长, 输送 速度快; 3 个季节仅有极少的轨迹数(少于 $10 \%$ )属于
第 4 类, 由瓦里关东部或东南部(西宁和兰州)迂回到 达瓦里关, 路径很短. 夏季, 能代表空间特征的典型 轨迹气团为 4 类, 与春、秋和冬季不同, 来自瓦里关 东南部, 途经西宁和兰州的轨迹数和来自甘肃和内 蒙中部一带的轨迹数百分比增加, 第 1 类和 4 类分别 占了总轨迹数的 $27 \%$ 和 $34 \%$; 第 2 类和第 3 类分别占 了 $24 \%$ 和 $16 \%$, 代表来自新疆东部和青海西北部、甘 肃省中部的气团类型.

根据大气 $\mathrm{CH}_{4}$ 浓度时间序列及本底值篮分结果, 因观测期间 $\mathrm{CH}_{4}$ 无呈现增长或降低趋势, 因此取各 个季节的多年平均本底浓度作为判断某一时刻的观 测值为污染浓度或本底浓度的临界值 (春、夏、秋和 冬分别为 $1831.2,1835.3,1831.3$ 和 $1831.5 \mathrm{ppb}$ ). 为了 更真实的反映大气输送对本底大气 $\mathrm{CH}_{4}$ 浓度的影响, 本论文中将代表受到 $\mathrm{CH}_{4}$ 吸收汇影响的数据排除, 再进行聚类统计分析, 轨迹聚类统计分析结果见表 1. 不同季节的 4 类轨迹气团获得的大气 $\mathrm{CH}_{4}$ 区域本 底浓度均无显著差异, 进一步证实了采用局部近似 回归法进行瓦里关大气 $\mathrm{CH}_{4}$ 浓度本底值篮分的合理

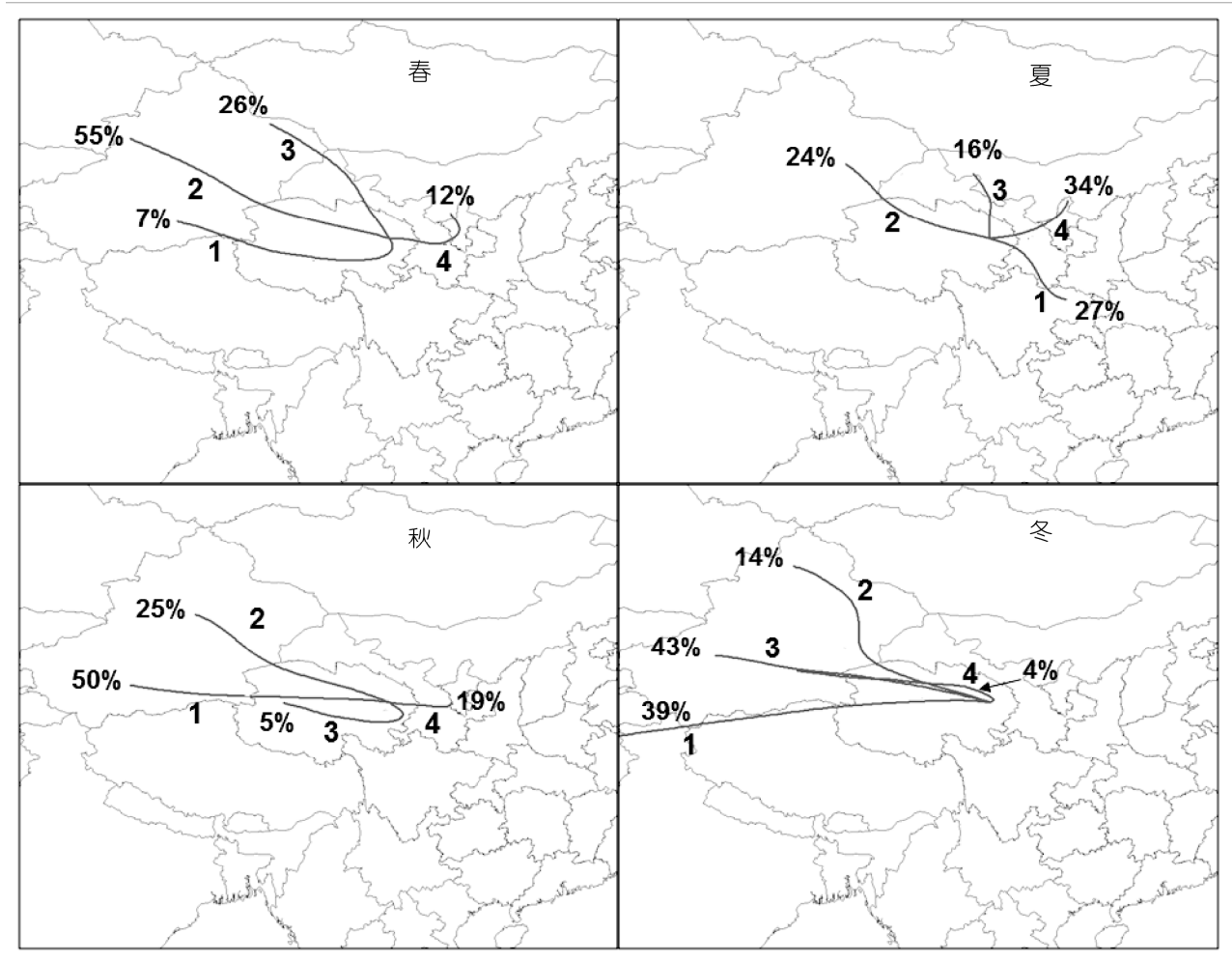

图 6 不同季节瓦里关轨迹聚类特征

每条聚类的轨迹的数字代表轨迹序列, 百分数表示该类轨迹所占总轨迹的百分比 
表 1 不同季节瓦里关大气 $\mathrm{CH}_{4}$ 浓度轨迹聚类统计分析结果

\begin{tabular}{|c|c|c|c|c|c|c|c|}
\hline & \multirow{2}{*}{ 轨迹簇类 } & \multicolumn{3}{|c|}{ 区域本底状况 } & \multicolumn{3}{|c|}{ 污染状况 } \\
\hline & & 轨迹数 & $\mathrm{CH}_{4}$ 平均值 $(\mathrm{ppb})$ & 标准偏差 (ppb) & 轨迹数 & $\mathrm{CH}_{4}$ 平均值 $(\mathrm{ppb})$ & 标准偏差 (ppb) \\
\hline \multirow{4}{*}{ 春 } & 1 & 22 & 1824.8 & 5.1 & 36 & 1841.6 & 6.7 \\
\hline & 2 & 187 & 1825.2 & 3.6 & 279 & 1841.1 & 8.9 \\
\hline & 3 & 38 & 1825.7 & 3.7 & 177 & 1845.5 & 11.0 \\
\hline & 4 & 26 & 1825.2 & 4.8 & 77 & 1844.2 & 10.3 \\
\hline \multirow{4}{*}{ 夏 } & 1 & 60 & 1828.2 & 5.8 & 245 & 1860.6 & 19.2 \\
\hline & 2 & 152 & 1827.5 & 5.6 & 115 & 1843.9 & 8.3 \\
\hline & 3 & 55 & 1828.5 & 4.7 & 120 & 1844.5 & 7.7 \\
\hline & 4 & 112 & 1830.3 & 4.0 & 266 & 1848.2 & 11.8 \\
\hline \multirow{4}{*}{ 秋 } & 1 & 264 & 1823.3 & 4.4 & 249 & 1847.1 & 14.9 \\
\hline & 2 & 121 & 1823.8 & 4.5 & 138 & 1842.1 & 10.1 \\
\hline & 3 & 5 & 1828.2 & 3.0 & 50 & 1847.2 & 11.9 \\
\hline & 4 & 11 & 1828.2 & 2.0 & 183 & 1861.1 & 16.9 \\
\hline \multirow{4}{*}{ 冬 } & 1 & 151 & 1824.2 & 4.9 & 145 & 1847.2 & 15.8 \\
\hline & 2 & 22 & 1826.5 & 3.8 & 84 & 1852.9 & 13.5 \\
\hline & 3 & 109 & 1824.8 & 4.6 & 219 & 1848.3 & 16.2 \\
\hline & 4 & 6 & 1826.6 & 4.2 & 27 & 1863.5 & 25.1 \\
\hline
\end{tabular}

性. 而各个季节各类轨迹团对应的污染浓度均比本 底浓度高出 20 40 ppb, 说明排放源的长距离输送作 用. 以下主要讨论来自不同气团的大气 $\mathrm{CH}_{4}$ 污染浓 度特征。

对于污染状况, 春季, 来自第 3 类轨迹空气团对 会明显抬升 $\mathrm{CH}_{4}$ 浓度, 使其浓度增加, 可能是气团途 径区域排放源的长距离输送的结果, 说明该区域可 能是 $\mathrm{CH}_{4}$ 的潜在源区; 此外, 来自第 3 类气团的大气 $\mathrm{CH}_{4}$ 浓度也较高(虽然其轨迹数目较少), 明显受到人 口较稠密、工业发达的兰州、西宁等区域排放源远距 离输送的影响. 夏季, 来自第 1 类轨迹的 $\mathrm{CH}_{4}$ 浓度值 最高, 且其标准偏差也最大, 说明甘肃兰州及西宁等 城市区域人类活动的排放影响很大; 其次是来自甘 肃省中部和宁夏西北部农业区的第 4 类轨迹气团也 会小幅抬升 $\mathrm{CH}_{4}$ 浓度, 可能主要是工商业活动及夏 季黄河流域水稻田种植的 $\mathrm{CH}_{4}$ 排放的长距离输送. 秋季, 第 4 类轨迹 $\mathrm{CH}_{4}$ 浓度值最高, 轨迹数多, 对 $\mathrm{CH}_{4}$ 浓度贡献很大, 主要是来自兰州及西宁的高污染 气团的影响; 第 1 类轨迹对应的 $\mathrm{CH}_{4}$ 污染浓度也很高, 且轨迹所占比例最大, 主要受新疆中南部农业区和 青海西北部地区气团的影响. 第 3 类轨迹经由青海中 部到瓦里关东南部后又向西北折回, 到达瓦里关, 所 对应的 $\mathrm{CH}_{4}$ 浓度也较高, 但其轨迹数少, 实际对高
$\mathrm{CH}_{4}$ 值的贡献不大. 冬季, 来自第 2 类和第 4 类轨迹 对应的 $\mathrm{CH}_{4}$ 浓度最高, 为潜在的源区, 但这两类轨迹 并不是主导气流, 因此对大气 $\mathrm{CH}_{4}$ 浓度贡献不大. 综 上所述, 大气 $\mathrm{CH}_{4}$ 浓度的抬升除了受到来自瓦里关 东南或东部地区(西宁、兰州)人口密集、工商业发达 的地区的污染气团的影响外, 来自甘肃或宁夏黄河 沿岸的农业区(如水稻种植区)气团也会使 $\mathrm{CH}_{4}$ 浓度抬 升, 并且尤其在夏季明显.

\section{$3.5 \mathrm{CH}_{4}$ 源区分布概率特征}

潜在来源贡献算法(potential source contribution function, PSCF) 是基于轨迹分析方法来识别源区的方 法, 也称为滞留时间分析 (residence time analysis, RTA). 它是一个条件概率函数, 主要利用后向轨迹 来计算和描述可能的源区位置, 反映了一定空间覆 盖率的空气团在到达测点之前的滞留时间 ${ }^{[25,26]}$. 由 于接近起始点的轨迹覆盖率的问题, 该方法的角度 分辨率较好, 但是径向(或辐射)分辨率较差 ${ }^{[27]}$. 其不 足之处是当样品浓度略高或远高于污染临界值时, 将获得所有格点同样大小的 PSCF 值, 导致无法很好 地区分源的强弱. 本文将所选研究的被轨迹覆盖的 地理空间区域 $\left(25^{\circ} \sim 50^{\circ} \mathrm{N}, 80^{\circ} \sim 110^{\circ} \mathrm{E}\right)$ 网格化, 分成 $0.3^{\circ} \times 0.3^{\circ}$ 的水平网格 (距离地面高 $500 \mathrm{~m}$ ), 然后针对 
所研究期间内的所有轨迹, 来计算每个网格内的轨 迹出现概率(PSCF 值), 也就是所有气团在某网格内 总的滞留时间除以总时间. PSCF 是一个位置函数, 由 格点指数 $i$ 和 $j$ 来定义, 当轨迹数穿过第 $i j$ 个格点的时 候, 被记为 $n_{i j}$. 超过本底值的轨迹数被定义为 $m_{i j}$. 任 何一个大于本底浓度值的格点的概率被定义为 ${ }^{[28]}$

$$
\operatorname{PSCF}_{i j}=m_{i j} / n_{i j} \text {. }
$$

为了减少该方法无法区分源强弱的局限性，采 用了一个权重因子 $W_{i j}$ 以避免上述效应. 这种方法使 得当在一个特定格点的节点总数低于 3 倍该节点的 平均值的时候, PSCF 的值有所降低. 该权重因子 $W_{i j}$ 定义如下:

$$
W_{i j}=\left\{\begin{array}{ll}
1.00, & n_{i j}>80, \\
0.70, & 20<n_{i j} \leqslant 80, \\
0.42, & 10<n_{i j} \leqslant 20, \\
0.05, & n_{i j} \leqslant 10 .
\end{array} .\right.
$$

2002 2006 年不同季节大气 $\mathrm{CH}_{4}$ 的源区分布概
率特征(图 7). 图中颜色的深浅代表了排放源分布的 概率大小, 某地区颜色越深, 说明该地区是强的 $\mathrm{CH}_{4}$ 排放源的概率越高, 否则, 反之. 春季, WPSCF 较大 值(深红到红色区域)呈东南-西北方向分布, 覆盖了 青海北部、甘肃省中部的大片区域, 并分别向新疆南 部地区和东北地区延伸. WPSCF 的高值集中在 3 个 区域,一是新疆、青海和甘肃三省的交界处; 二是瓦 里关周边及距其约 $100 \mathrm{~km}$ 的西宁地区; 三是甘肃省 中部地区, 是 $\mathrm{CH}_{4}$ 的潜在源区, 与聚类分析结果比较 吻合. 此外, 新疆南部地区和兰州地区也可见较小深 红区域, 可能主要是生物质燃烧和人类活动的排放. 夏季, $\mathrm{CH}_{4}$ 的潜在源区主要集中在瓦里关东部至东南 部地区，包括距离瓦里关较近的西宁、甘肃省中部至 南部大部分区域、陕西与四川交界处, 还一直延伸覆 盖到四川省东北部的大片区域, 说明了夏季大气 $\mathrm{CH}_{4}$ 的来源主要是东南部地区人类活动的排放. 秋季, 瓦 里关东南部地区的深红区域范围有所收缩，但 WPSCF 值仍然很大, 是 $\mathrm{CH}_{4}$ 的潜在源区. 此时源区

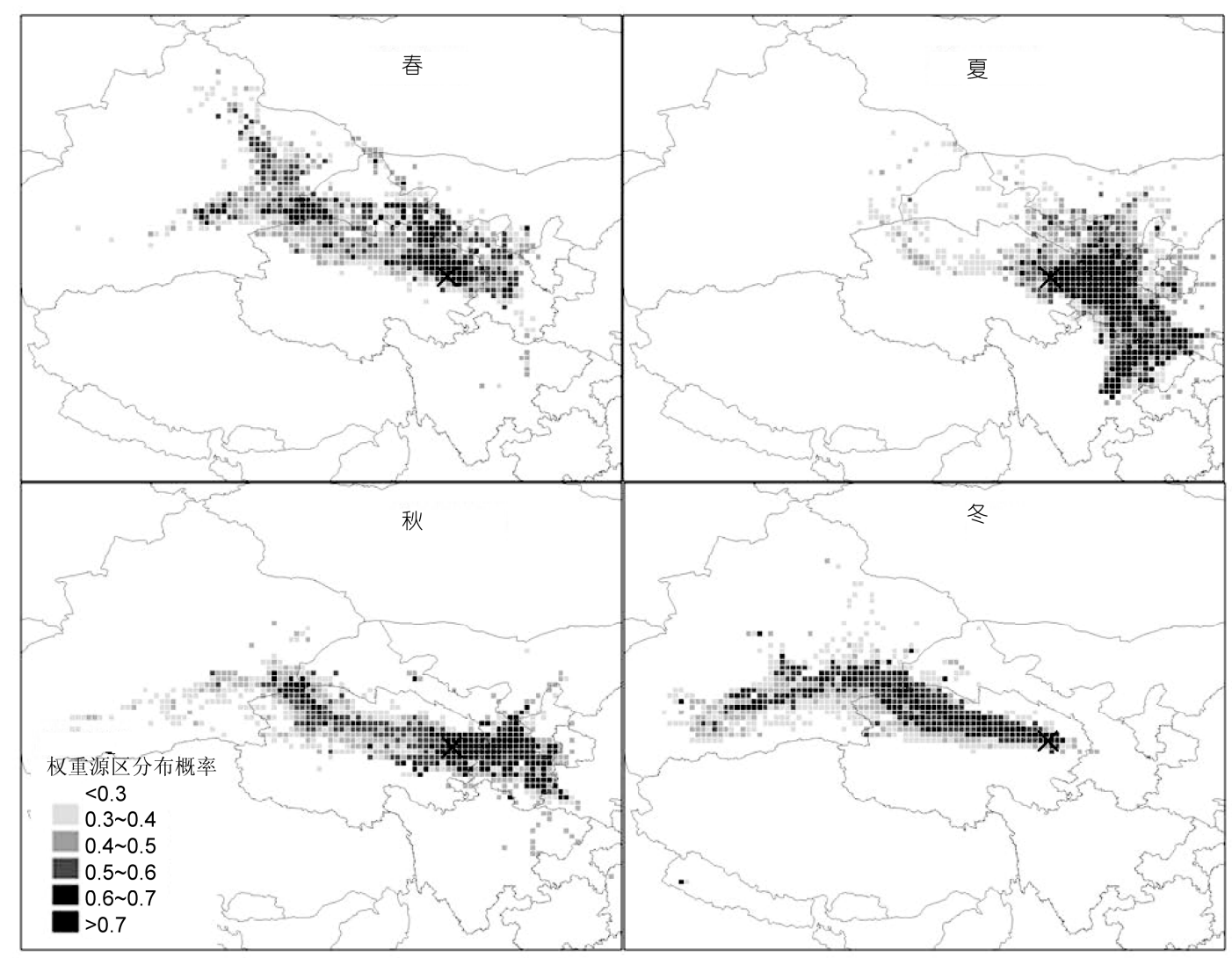

图 7 不同季节大气 $\mathrm{CH}_{4}$ 的源区分布概率特征 
开始向青海西北地区呈带状扩展, 在新疆、青海和甘 肃交界处出现 WPSCF 值的极大值. 冬季, 瓦里关东 南部深红区域消失, 而呈现出自瓦里关向青海西北 部地区扩展, 在新疆、甘肃和青海交界处聚拢, 并向 新疆南部地区延伸的带状分布特征. 其中, 再次在青 海西北部(格尔木地区)、3 省(新疆、甘肃和青海)交界 处以及新疆南部地区出现 WPSCF 极大值, 说明该区 域成为 $\mathrm{CH}_{4}$ 的强源区的概率极高.

\section{4 结论}

（1）利用局部近似回归法对大气 $\mathrm{CH}_{4}$ 浓度进行 了本底值篮分, 结果显示, 大气 $\mathrm{CH}_{4}$ 浓度本底数据百 分比占 58\%, 波动小(约 $38 \mathrm{ppb}$ ); 分别约 26\% 和 $16 \%$ 的数据被篎分为源排放值和汇吸收值, 大气 $\mathrm{CH}_{4}$ 非 本底浓度波动较大, 反映了瓦里关大气 $\mathrm{CH}_{4}$ 浓度受
较强的局地或区域源汇影响.

（2）不同季节大气 $\mathrm{CH}_{4}$ 浓度日变化规律明显, 其 变化特征是源汇强度变化和对流层大气热力、动力学 等扩散输送条件相互作用的结果. $\mathrm{CH}_{4}$ 多年平均季节 变化呈夏季高、冬春低的特征, 与北半球的高海拔站 点(美国 Mauna Loa 和 Niwot Ridge)呈相反的变化趋 势, 主要与瓦里关独特的源汇变化以及气团污染物 输送特征密切相关.

(3) 采用 5 天后向轨迹聚类研究大气 $\mathrm{CH}_{4}$ 的长距 离输送特征, 结果表明, 大气 $\mathrm{CH}_{4}$ 浓度高值与来自青 海西北部(尤其是格尔木地区)和瓦里关东北或东部 (西宁和兰州)的空气团轨迹关系密切, 是 $\mathrm{CH}_{4}$ 潜在的 源区; 此外, 来自甘肃或宁夏黄河沿岸一带的农业区 气团会使 $\mathrm{CH}_{4}$ 浓度抬升, 夏季尤其明显, 显示了 $\mathrm{CH}_{4}$ 的农业排放源. 而来自西藏西北部、青海和新疆南部 地区气流相对清洁, 不会导致 $\mathrm{CH}_{4}$ 浓度抬升。

\section{参考文献}

1 Battle M, Bender M, Sowers T, et al. Atmospheric gas concentrations over the past century measured in air from firn at the south pole. Nature, 1996, 383: 231-235

2 Lelieveld J, Crutzen P J, Dentener F J. Changing concentration, lifetime and climate forcing of atmospheric methane. Tellus, 1998, 50: $128-150$

3 Chappellaz J, Barnola J M, Raynaud D, et al. Ice-core record of atmospheric methane over past 160000 years. Nature, 1990, 345: 127-131

4 Blake D R, Mayer E W, Tyler S C, et al. Global increase in atmospheric methane concentrations between 1978 and 1980. Geophys Res Lett, 1982, 9: 477-480

5 Rasmussen R, Khalil M. Atmospheric methane $\left(\mathrm{CH}_{4}\right)$ : Trends and seasonal cycles. J Geophys Res, 1981, 86: 9826-9832

6 Dlugokencky E J, Steele L P, Lang P M, et al. The growth rate and distribution of atmospheric methane. J Geophys Res, 1994, 99: 17021-17043

7 Crosson E R. A cavity ring-down analyzer for measuring atmospheric levels of methane, carbon dioxide and water vapor. Appl Phys, 2008, 92: 403-408

8 藏昆鹏, 周凌晞, 方双喜, 等. 新型 $\mathrm{CO}_{2}$ 和 $\mathrm{CH}_{4}$ 混合标气标校流程及方法. 环境化学, 2011, 30: 511-516

9 Zhou L X, Worthy D E, Lang J P M, et al. Ten years of atmospheric methane observations at a high elevation site in western China. Atmos Environ, 2004, 38: 7041-7054

10 WDCGG. World Data Center for Greenhouse Gases (WDCGG), Data Summary 34. Japan: Tokyo, 2010. 33: 1-105

11 Zhang F, Zhou L X, Novelli P C, et al. Evaluation of in situ measurements of atmospheric carbon monoxide at mount Waliguan. Atmos Chem Phys, 2011, 11: 5195-5206

12 Zhou L X, Tang J, Wen Y P, et al. The impact of local winds and long-range transport on the continuous carbon dioxide record at mount Waliguan, China. Tellus B, 2003, 55: 145-158

13 Zhou L X, Conway T J, White J W C, et al. Long-term record of atmospheric $\mathrm{CO}_{2}$ and stable isotopic ratios at Waliguan observatory: Background features and possible drivers, 1991-2002. Glob Biogeochem Cycle, 2005, GB3021, doi: 10.1029/2004GB002430

14 Zhou L X, White J W C, Conway T J, et al. Long-term record of atmospheric $\mathrm{CO}_{2}$ and stable isotopic ratios at Waliguan observatory: Seasonally averaged 1991-2002 source/sink signals, and a comparison of 1998-2002 record to the 11 selected sites in the northern hemisphere. Glob Biogeochem Cycle, 2006, GB2001, doi: 10.1029/2004GB002431 
15 周凌晞, 汤洁, 张晓春, 等. 气相色谱法观测本底大气中的甲烷和二氧化碳. 环境科学学报, 1998, 18: 356-361

16 Ruckstuhl A F, Henne S, Reimann S, et al. Robust extraction of baseline signal of atmospheric trace species using local regression. Atmos Meas Tech Discuss, 2010, 3: 5589-5612

17 Andreas F R, Matthew P J, Robert W F, et al. Baseline subtraction using robust local regression estimation. J Quant Spect Radiat Transf, 2001, 68: 179-193

18 杨博. 青藏高原冬季放牧牦牛甲烷排放的初步研究. 硕士毕业论文. 兰州: 甘肃农业大学, 2009

19 王明星, 戴爱国, 黄俊, 等. 中国 $\mathrm{CH}_{4}$ 排放量的估算. 大气科学, 1993, 17: 52-64

20 Dlugokencky E J, Myers R C, Lang P M, et al. Conversion of NOAA atmospheirc dry air $\mathrm{CH}_{4}$ mole fractions to a gravimetrically prepared standard scale. J Geophys Res, 2005, D18306, doi: 10.1029/2005JD006035

21 Ma J, Liu H, Hauglustaine D. Summertime tropospheric ozone over China simulated with a regional chemical transport model: 2. Source contribution and budget. J Geophys Res, 2002, doi: 10.1029/2001JD001355

22 Draxler R, Hess G D. An overview of the HYSPLIT_4 modelling system for trajectories, dispersion, and deposition. Aust Met Mag, 1998, 47: 295-308

23 颜鹏, 黄健, Draxler R, 等. 北京地区 $\mathrm{SO}_{2}$ 污染的长期模拟及不同类型排放源影响的计算与评估. 中国科学 $\mathrm{D}$ 辑: 地球科学, 2005, 35: $167-176$

24 Sirois A, Bottenheim J W. Use of backward trajectories to interpret the 5-year record of PAN and $\mathrm{O}_{3}$ ambient air concentrations at Kejimkujik National Park, Nova Scotia. J Geophys Res, 1995, 100: 2867-2881

25 Begum B A, Kim E, Jeong C H, et al. Evaluation of the potential source contribution function using the 2002 Quebec forest fire episode. Atmos Environ, 2005, 39: 3719-3724

26 Ashbaugh L L, Malm W C, Sadeh W Z. A residence time probability analysis of sulfur concentrations at Grand Canyon National Park. Atmos Environ, 1985, 19: 1263-1270

27 Vasconcelos L A P, Kahl J D W, Liu D, et al. Spatial resolution of a transport inversion technique. J Geophys Res, 1996, 101: 19337-19342

28 Polissar A V, Hopke P K, Paatero P, et al. The aerosol at Barrow, Alaska: Long-term trends and source locations. Atmos Environ, 1999, 33: $2441-2458$ 